\title{
Effectiveness of tutorials for promoting educational integrity: a synthesis paper
}

\author{
Brenda M. Stoesz ${ }^{1 *}$ (D) and Anastassiya Yudintseva ${ }^{1,2}$
}

\author{
* Correspondence: Brenda.Stoesz@ \\ umanitoba.ca \\ ${ }^{1}$ Centre for the Advancement of \\ Teaching and Learning, University \\ of Manitoba, 65 Dafoe Road, \\ Winnipeg, MB R3T 2N2, Canada \\ Full list of author information is \\ available at the end of the article
}

\begin{abstract}
The prevalence of plagiarism, cheating, and other acts of academic dishonesty may be as high as $80 \%$ in populations of high school and post-secondary students. Various educational interventions have been developed and implemented in an effort to educate students about academic integrity and to prevent academic misconduct. We reviewed the peer-reviewed research literature describing face-to-face workshops, elearning tutorials, or blended approaches for promoting academic integrity and the effectiveness of these approaches. In general, the educational interventions were described as effective in terms of satisfaction with the intervention, and changes in students' attitudes and knowledge of academic integrity. Few studies provided evidence that the educational interventions changed student behaviour or outcomes outside the context of the intervention. Future research should explore how participation in educational interventions to promote academic integrity are linked to long-term student outcomes, such as graduate school admission, alumni career success, service to society, and personal stability.
\end{abstract}

Keywords: Academic integrity, Teaching and learning, Tutorials, Student outcomes

Depending on the study, upwards of $80 \%$ undergraduate and graduate students have admitted to some form of cheating on assignments, tests, or exams (e.g., "Dee and Jacob, 2012; Maxwell et al., 2006; Oran et al., 2015; Patrzek et al., 2015). Many students are familiar with behaviours that constitute academic misconduct and assert that these acts are wrong (Davis et al., 2012); whereas others are unaware of the seriousness of these behaviours or feel their actions are justified (Barnhardt and Ginns, 2016; Wideman, 2011). Even when students $d o$ regard plagiarism as a serious act of academic dishonesty, they may still engage in the behaviour unintentionally because they are ill equipped with the skills necessary to paraphrase and cite sources correctly (Greenberger et al., 2016; Roig, 1999). Moreover, students may feel that the pressure to obtain high academic standing outweighs the consequences of wrongdoing (Galloway and Conner, 2015) or may not understand the importance of integrity beyond their immediate academic environment.

Indeed, practicing dishonest behaviours in the classroom setting (regardless of the academic discipline) is associated with workplace dishonesty. For example, Krueger (2014) reported that the frequencies of dishonest behaviours in the classroom and clinical settings were positively correlated, and a large proportion of nursing students (54\%) reported engaging in false documentation, reporting home visits that did not occur, and discussing confidential patient information outside of the clinical setting.

(C) The Author(s). 2018 Open Access This article is distributed under the terms of the Creative Commons Attribution 4.0 International License (http://creativecommons.org/licenses/by/4.0/), which permits unrestricted use, distribution, and reproduction in any medium, provided you give appropriate credit to the original author(s) and the source, provide a link to the Creative Commons license, and indicate if changes were made. 
Lucas and Friedrich (2005) found a significant negative relationship between scores on measures of academic dishonesty and employment integrity in various fields (food, clerical, retail, and home and childcare services, retail services, parks and recreation, and education). Similarly, Nonis and Swift (2001) reported a strong positive correlation between the frequencies of cheating in academic and corporate settings. Thus, addressing academic dishonesty in education is important for reasons that go well beyond the borders of postsecondary institutions.

Postsecondary institutions have taken steps to foster academic integrity through campus campaigns, developing disciplinary policies and procedures, encouraging instructors to report academic misconduct (Bertram Gallant, 2008; "Curtis et al., 2013), and implementing honour codes ("Chertok et al., 2013). Offices of integrity and teaching and learning centres have been established to deal with allegations of academic misconduct and support instructors' practice of sound pedagogy to encourage deep learning, thereby promoting academic integrity indirectly. Aligning faculty and students' knowledge and seriousness of various types of academic misconduct is also recognized as important for reducing the number of cases (Bailey, 2001; Krueger, 2014).

The vast majority of the research on academic integrity examines the prevalence of cheating or plagiarism, and factors (e.g., age, gender, level of education, cultural background,) associated with engaging in dishonest behaviours in the educational setting. Some research has examined students' perceptions of the seriousness of behaviours considered by educational institutions as examples of academic misconduct. A smaller literature describes the development of educational interventions to decrease cases of academic misconduct. These educational interventions often focus on plagiarism prevention by paraphrasing and citing sources properly, or educating students about consequences of academic misconduct, however, little is known about the effectiveness of these interventions or the quality of the studies examining intervention success. To this end, we examined the literature describing face-to-face workshops, e-learning tutorials, and blended learning approaches for educating students (in any discipline) about academic integrity and their ability to change attitudes and increase knowledge and skills concerning academic integrity, reduce cases of academic dishonesty, and improve student outcomes. Our second aim was to identify the demographic or contextual factors in these studies that may have contributed to the success of the educational intervention.

\section{Method}

\section{Search strategy}

Our review process was based on the Preferred Reporting Items for Systematic Reviews and Meta-analyses (PRISMA) statement (Moher et al., 2009; Shamseer et al., 2015). We conducted electronic searches for studies published in English using the databases CINAHL, Educational Resources Information Center (ERIC), ProQuest Dissertations and Theses A\&I, PsycINFO, PubMed, Science Direct, Scopus, and Web of Science. Our search (November 16, 2016) used the following keywords: (a) 'academic integrity' OR 'academic dishonesty' OR 'academic misconduct'; AND (b) tutorial OR remedial instruction OR simulation OR 'experiential learning' OR teaching OR methods OR game OR online; AND (c) AND plagiarism OR 'self plagiarism' OR 'self-plagiarism' OR cheating OR 'duplicate submission' OR personation OR impersonation OR academic 
fraud OR 'inappropriate collaboration' OR 'intellectual property' OR 'copyright'. No limitations were set for date of publication. We located 1035 references (published 1976-2016) in this initial search and eliminated 30 duplicates (see Fig. 1).

\section{Selection of studies for targeted review}

Two reviewers independently screened the titles and abstracts of 1005 articles to determine inclusion eligibility based on these criteria: (1) the study must have offered a Method section that clarified the research design; (2) participants must have been postsecondary students; and (3) the study must have focused on determining the effectiveness of face-to-face workshops or e-Learning tutorials or combinations of the two forms of content delivery (i.e., blended approach) to promote academic integrity. A workshop was defined as "a brief intensive educational program for a small group of people that focuses on knowledge and skills in a particular area of content" (Miriam-Webster, n.d.). A tutorial was defined as "self-paced instructional program providing step by step information about a concept" (Web Finance, n.d.). Blended instruction was defined as a combination of "any form of instructional technology (e.g., videotape, CD-ROM, web-based training, film) with face-to-face instructor-led training" (Driscoll, 2002, p. 54).

Articles were excluded if they: (1) were book reviews or critical discussion papers; (2) focused on the development of the educational intervention without providing details on effectiveness; or (3) focused on attitudes and/or prevalence of academic misconduct only. In the event that an abstract was missing, the default procedure was to include

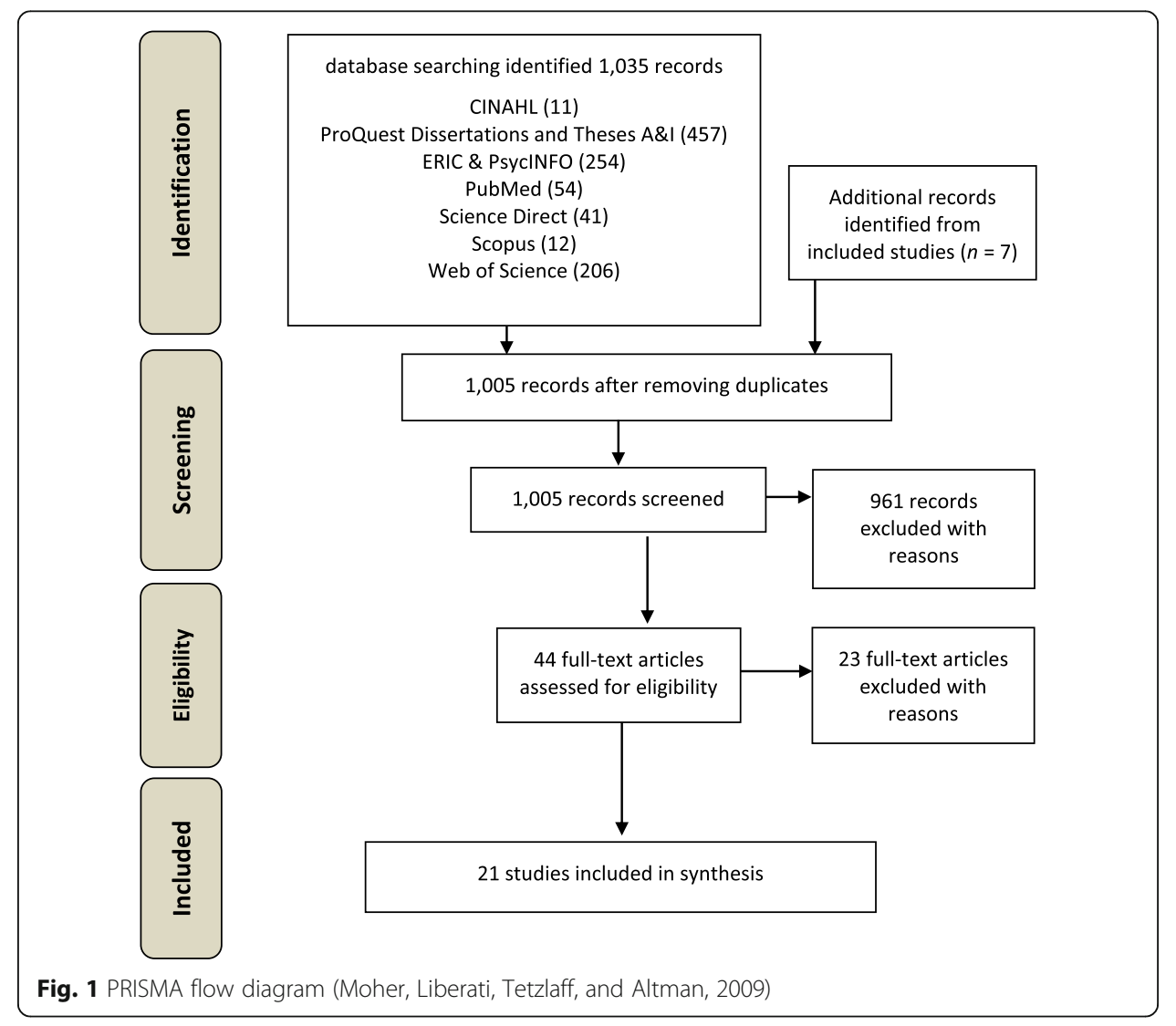


the reference for full text review. During the screening process, we excluded 961 articles that did not meet the inclusion criteria. Inclusion/exclusion was based on agreement between two reviewers. In cases of non-consensus, a third review was obtained for decision. We scanned the reference lists of the studies that met our inclusion criteria $(n=44)$ and identified 7 additional articles based on titles for full text review. We retrieved and examined 51 peer-reviewed publications in detail to determine their suitability, and excluded 30 that did not meet the inclusion criteria. Reviews on the effectiveness of educational interventions for promoting academic integrity were not identified in our search and screening process.

\section{Data extraction and analysis}

For selected articles, data were extracted using a predefined data extraction form with the following fields: author(s), publication date, study location, institution characteristics, study population, research design, delivery mode, specific educational content (e.g., academic integrity policies, documentation styles, and plagiarism), outcome variable(s), method(s) of analysis, main finding(s), and conclusions. Study limitations were noted; these may have been identified by the author(s) of the article or identified through our review of the study. Based on the extracted data, we categorized the articles by content delivery mode: (a) face-to-face workshop setting without supporting online learning components; (b) e-learning technology without further educational support in a traditional face-to-face educational setting; and (c) blended approaches. We extracted information related to the specific educational content (e.g., academic integrity policies, documentation styles, plagiarism) and four levels of evaluation used to assess the effectiveness of the educational intervention (Kirkpatrick, 1996): Level 1 (the learners' immediate reactions to or perceptions of the program); Level 2 (changes in knowledge, skills, or attitudes); Level 3 (changes in behaviour or application of the acquired knowledge in practice); and Level 4 (final tangible results, such as graduate school admission, alumni career success, service to society, and personal stability; Praslova, 2010).

To evaluate the quality of the studies, we implemented the Medical Education Research Study Quality Instrument (MERSQI), which consists of 10-items designed to assess the quality of experimental, quasi-experimental, and observational research studies in six domains (study design, sampling [number of institutions, response rate], type of data [self-assessment, objective measurements], validity of evaluation instrument, data analysis [level of sophistication, appropriateness], and outcomes) (Cook and Reed, 2015; Reed et al., 2007). The ratings for the outcome domain (item 10) were based on the Kirkpatrick's four-level training model (Kirkpatrick, 1996) (as outlined above). MERSQI items were selected for the scale based on discussions of research quality found in the literature. For each domain, raters identify the response option that best describes a component of the study; the response option is associated with a score. For example, for the study design domain, "Single-group cross-sectional or single-group posttest only" = 1; "Single-group pretest and posttest" = 1.5; "Nonrandomized, 2 group" $=2$; and "Randomized controlled trial" $=3$. For the type of data domain, "assessment by study participant" $=1$ and "Objective/Observer ratings" $=3$. In the outcome domain, "Satisfaction, attitudes, perceptions, opinions, general facts" = 1, "Knowledge, skills" = 1.5 , "Behaviors" $=2$, "Patient/health care outcome" $=3$. Operational definitions are 
provided to assist in the selection of an appropriate rating. An overall quality score (Range $=5.0-18.0)$ can be calculated by summing the ratings given in each domain. Evidence suggests that scores generated using the MERSQI are valid and reliable (Cook and Reed, 2015; Cook and West, 2012; Reed et al., 2007). For example, Cook and Reed reported interrater reliability coefficients for overall scores ranging from .68 to .95 for 26 studies evaluated, with a median overall score of 11.3 (Range = 8.9-15.1). Reed et al. found that overall MERSQI scores for 210 articles were associated with expert ratings of research quality $\left(r_{s}=.73\right)$, providing evidence for validity of overall scores.

The MERSQI was developed for assessing the quality of medical education research but was deemed appropriate for our purposes for several reasons. First, the MERSQI includes evaluation of domains that are important to evaluate in education research of other disciplines and topics involving interventions (e.g., academic integrity), and overlap with the research recommendations made by educational researchers and educational research organizations (Earle and Maynard, 2013; "Standards for Reporting on Humanities-Oriented Research in AERA Publications: American Educational Research Association," 2009). Second, the tool was relatively simple to use. Third, scores generated using the MERSQI allowed for quick numerical ratings for which to compare studies. We implemented the MERSQI as designed with one modification -"Patient/healthcare outcomes" was modified to "Student/society outcomes" (as per Praslova, 2010). Using the MERSQI, we (the two authors) evaluated all the studies independently. Individual ratings were then compared on an item-by-item basis, and an agreement score was computed for each article by dividing the number of agree-upon items by the total number of items (10) and expressing the result as a percentage. The mean agreement score was $80.5 \%(S D=11.6 \%$; Range $=60-100 \%)$. Disagreements between raters were resolved by consensus to determine domain and total MERSQI scores for each article.

\section{Results}

The studies reviewed were conducted in the United States (14), Australia (3), United Kingdom (1), Sweden (1), Qatar (1), and Taiwan (1). The articles were published in journals that focus on topics in psychology (6), education (4), library science (4), nursing (3), economics (1), social work (1), and sociology (1). Articles were published between 1995 and 2016. Eighteen studies used quantitative approaches and three used mixed methods to examine the effectiveness of the interventions. Our review identified that 8003 postsecondary students (7833 undergraduate and 170 graduate students) participated across 21 studies. The gender of students was identified in 13 studies with 1361 women and 736 men participating. Five studies reported information about the age range of participants: 17-19 years ("Bendriss et al., 2015), 18+ years ("Henslee et al., 2015), > 24 years (97\% of the sample; "Morgan and Hart, 2013), 18-42 years ("Schuetze, 2004), and < 20 (43.3\%), 20-24 (32.2\%), and $>24(24.5 \%)$ years ("Smedley et al., 2015).

\section{Educational intervention classification and effectiveness}

Ten articles described studies implementing the effectiveness of face-to-face instruction about academic integrity and related topics, 8 described e-learning tutorials, and 3 
described blended learning approaches. The interventions utilized the following teaching methods (which we defined as any approach, strategy, or activity that enables student learning): direct instruction $(n=16)$; practice in class or homework $(n=8)$; discussion $(n=5)$; syllabus outlining academic integrity policies and syllabus review $(n=2)$; quizzes $(n=4)$; and pledges $(n=1)$. The content areas of the interventions included academic integrity in general $(n=6)$, plagiarism and paraphrasing $(n=13)$, and writing and citing $(n=2)$.

\section{Face-to-face instruction}

Ten articles reported the results of studies examining the effectiveness of face-to-face (faculty-led) instruction of academic integrity and related topics (Table 1). The workshops used presentations and discussions about academic integrity, plagiarism, institutional policies, and/or avoiding plagiarism as the primary instructional strategies with the aim of providing resources, increase awareness, and reducing the risk of plagiarism. "Ford and Hughes (2012) reported that a brief workshop improved students' understanding of plagiarism; however, no statistical tests were conducted. "Morgan and Hart (2013) did not find differences in self-reported cheating or perceptions of cheating between groups of students who did and did not attend a brief academic integrity workshop. The researchers did report significant group differences in perceptions of the effectiveness of academic integrity policies after the intervention.

Along with direct instruction, six studies examined the effectiveness of completing activities ("Fenster, 2016; "Froese et al., 1995; "Landau et al., 2002) or homework assignments ("Barry, 2006; "Estow et al., 2011; "Schuetze, 2004) to improve paraphrasing skills and the proper usage of a particular documentation style. In these studies, the practical activities led to significant increases in scores on tests designed to assess attitudes, knowledge, and skills about plagiarism. Landau et al. also found that students who received feedback and/or examples of plagiarism were significantly more likely to detect plagiarism in a written passage and were more confident in their understanding of plagiarism.

"Elander et al. (2010) examined an intervention designed to teach students about authorship in an effort to help student with their writing and to avoid committing plagiarism. The intervention was integrated into existing courses, and sessions were delivered two to four weeks before assignment submission. The authors reported significantly increased confidence in writing, understanding authorship, and avoiding plagiarism, particularly for first year university students as evidence for intervention effectiveness. In addition to discussions about academic integrity and causes of cheating, "Trautner and Borland (2013) found that the sociological imagination teaching and learning approach encouraged students to view scenarios of academic dishonesty as both personal problems and public issues.

\section{E-learning}

Eight studies examined the effectiveness of self-paced e-learning academic integrity tutorials (Table 2). These tutorials consisted of modules that introduced students to appropriate paraphrasing, quoting, documentation styles, and strategies to avoid plagiarism (e.g., not procrastinating), using definitions and explicit examples as well as 


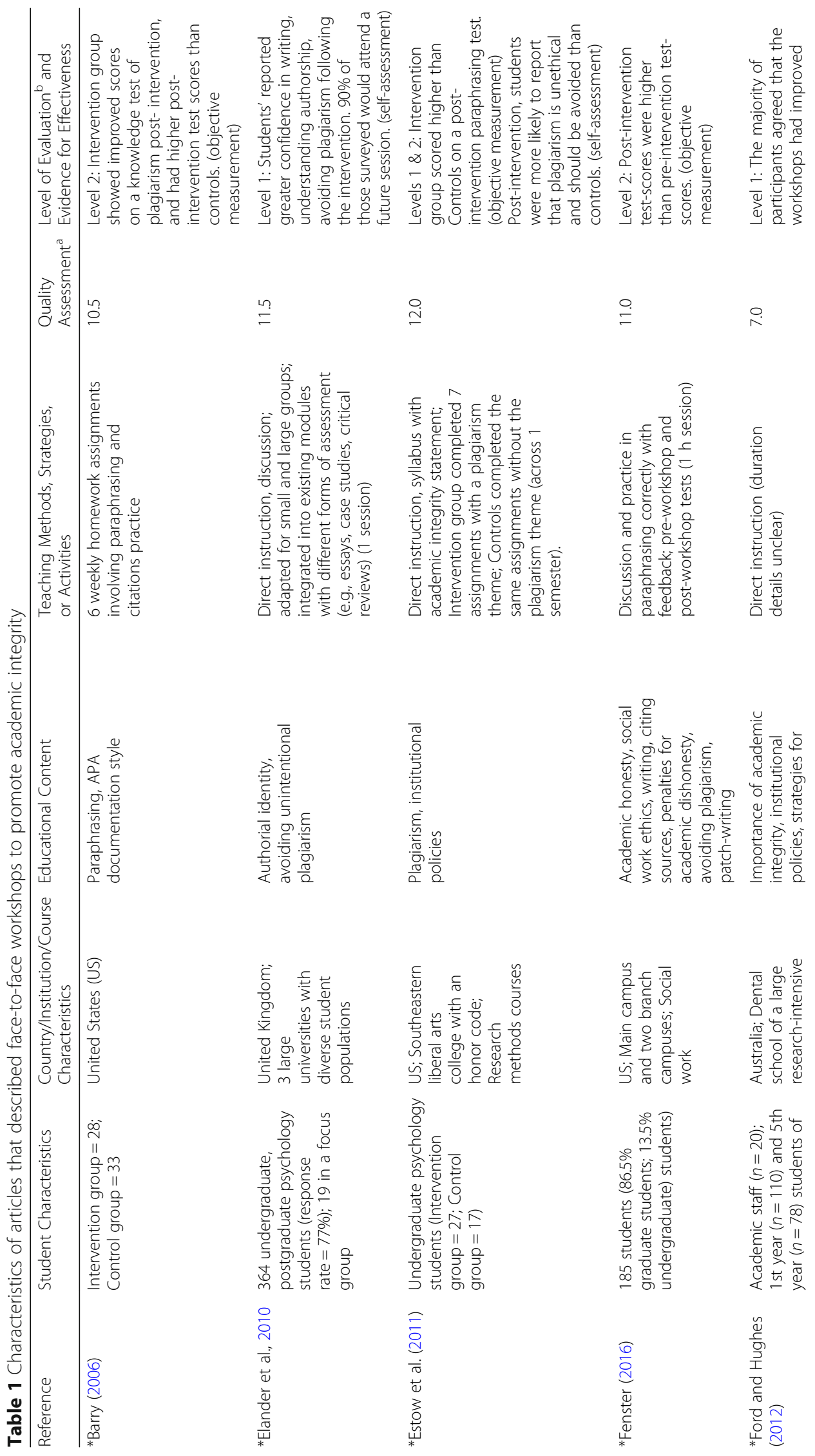




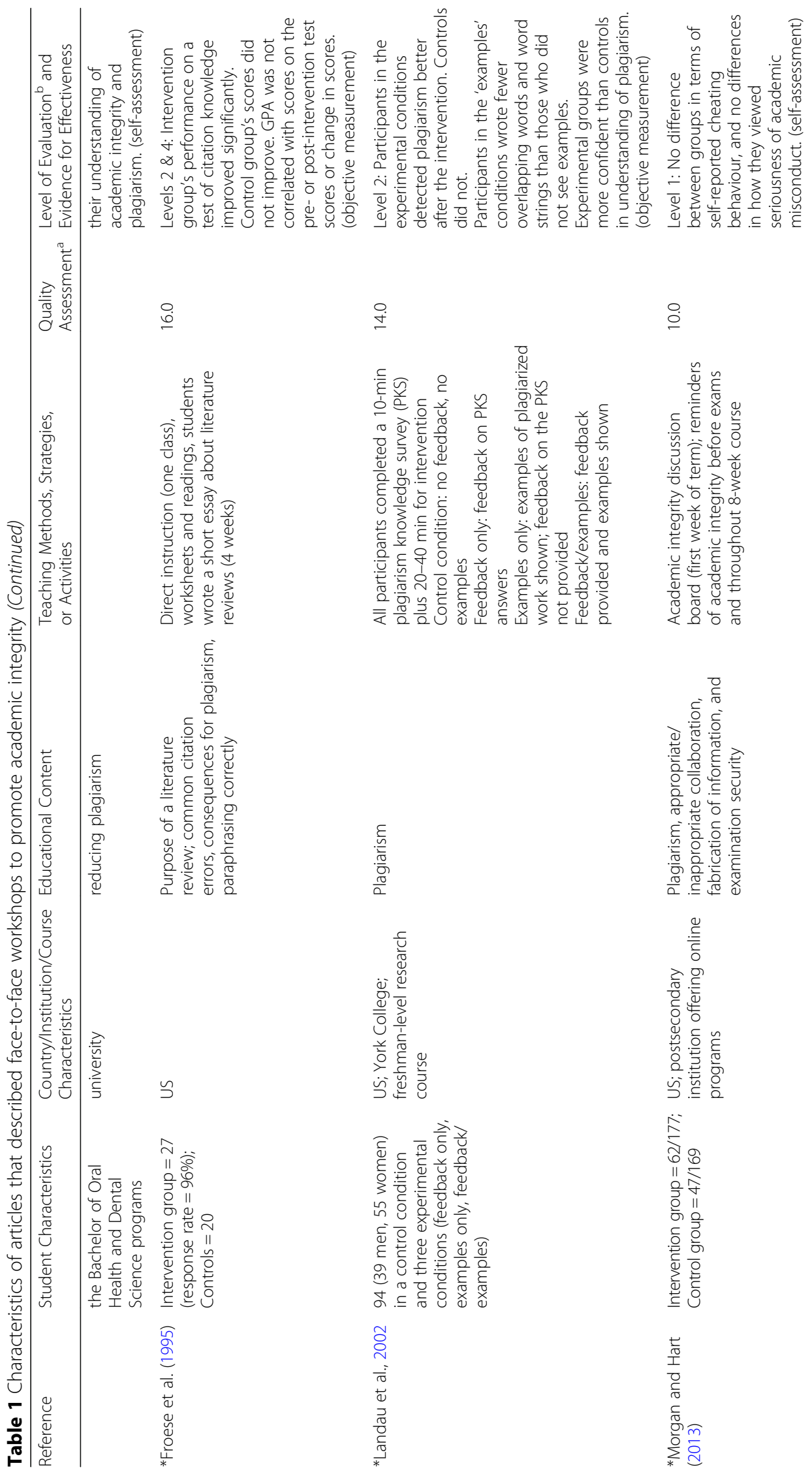




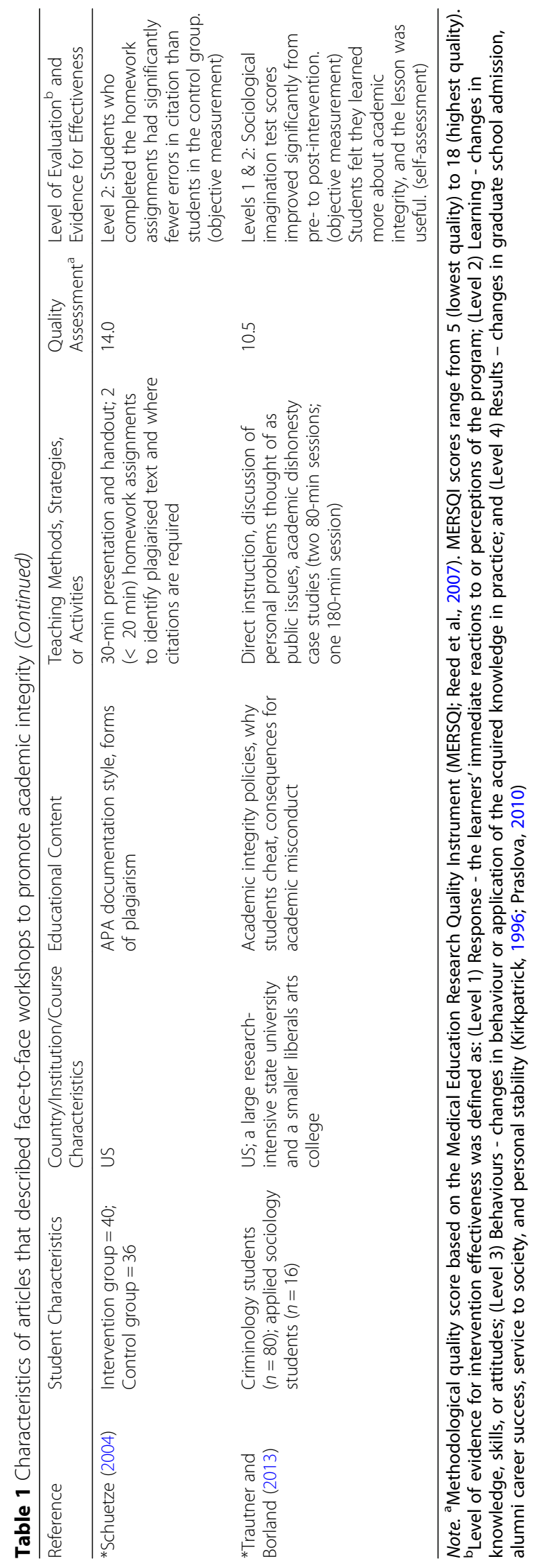




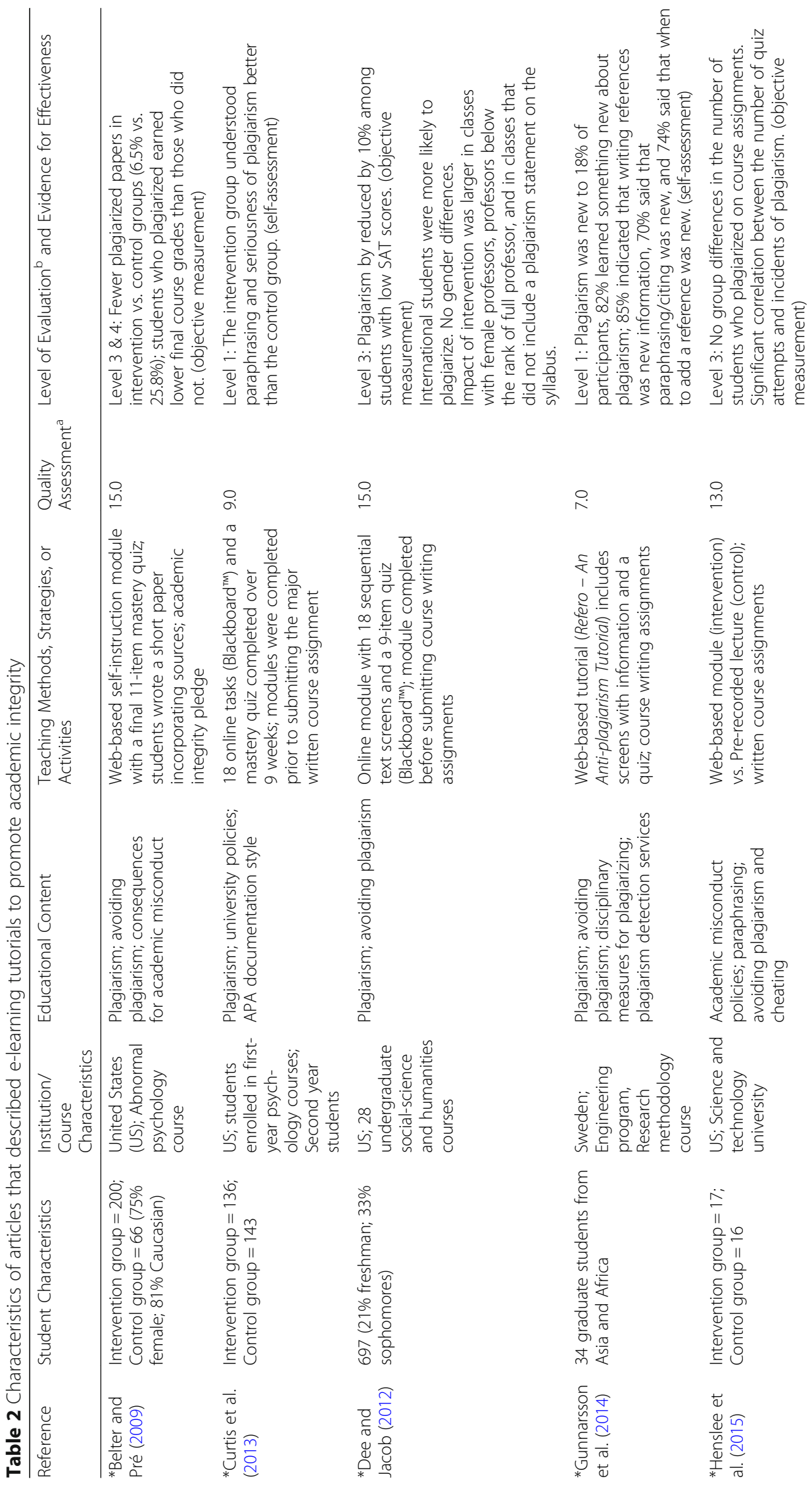




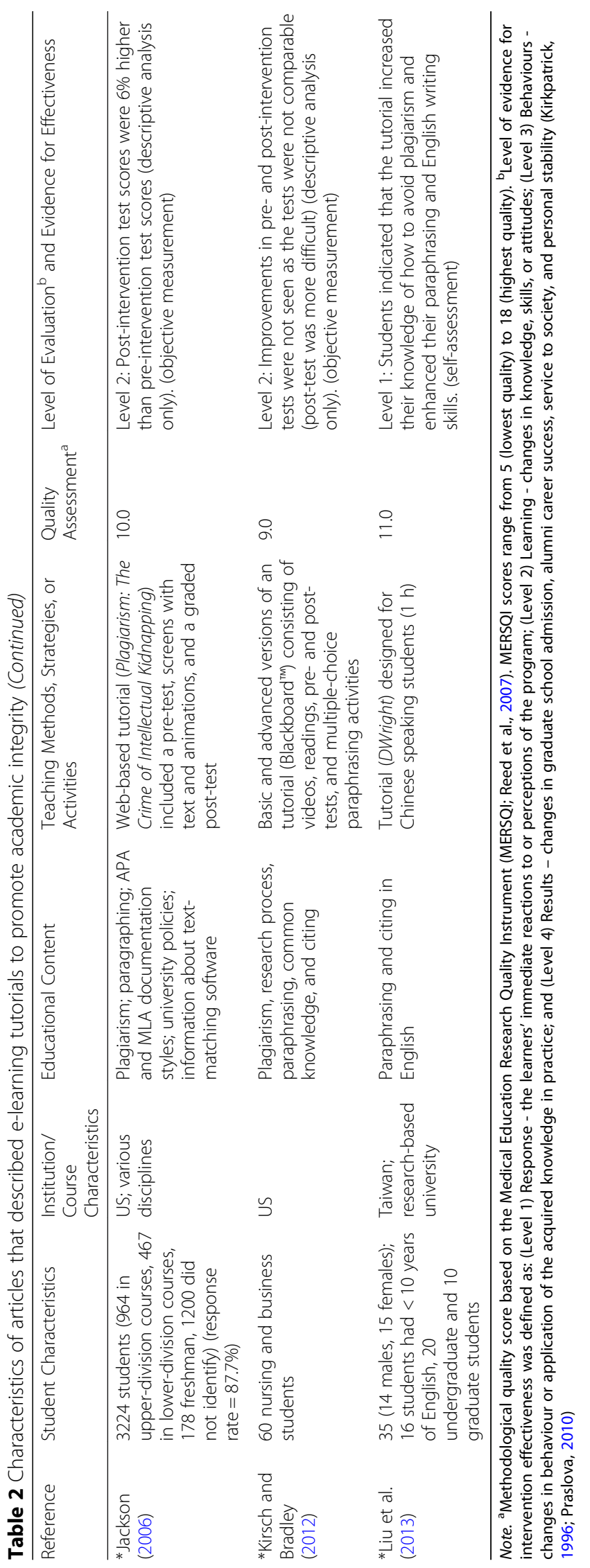


describing institutional policies and procedures regarding academic misconduct. Detailed and immediate feedback was provided to facilitate learning.

In five tutorials, students were required to complete short quizzes and practical activities ("Belter and Pré, 2009; "Curtis et al., 2013; "Dee and Jacob, 2012; "Henslee et al., 2015; "Kirsch and Bradley, 2012). Belter and Pré reported significantly fewer cases of plagiarism on written course assignments in the group of students who completed the tutorial compared to the group that did not, and students who did plagiarize earned significantly lower course grades. Examining the same tutorial, Henslee et al. found no differences in the number of cases of plagiarism in a group who completed the tutorial compared to a group who viewed a pre-recorded lecture; however, there was a significant positive correlation between the number of attempts on the mastery quiz and incidents of plagiarism. Three of the five studies examined the effectiveness of various tutorials delivered via a learning management system ("Curtis et al., 2013; "Dee and Jacob, 2012; "Kirsch and Bradley, 2012). Curtis et al. reported that the intervention group showed greater improvements in their understanding of paraphrasing and seriousness of plagiarism than the control group following the 9-week intervention. Dee and Jacob found that the tutorial reduced the likelihood of plagiarism by roughly $10 \%$ among students with low SAT scores, and that the impact of the intervention tended to be larger in classes with female professors, professors below the rank of full professor, and in classes that did not include a plagiarism statement on the syllabus. Interestingly, Kirsch and Bradly reported that some participants showed slight improvement in test scores following the intervention, whereas others scored lower on postcompared to pre-intervention tests. Rather than suggesting the intervention was not effective, participants may not have spent enough time or attention watching the videos or reading the material presented ("Kirsch and Bradley, 2012).

Three studies examined the effectiveness of the three web-based tutorials known as Refero (Andersson et al., 2008), Plagiarism: The Crime of Intellectual Kidnapping (Jackson, 2018), and DWright. "Gunnarsson, Kulesza, and Pettersson (2014) and "Liu, Lo, and Wang (2013) reported effectiveness in the form of student satisfaction with the tutorial, attitudes about academic integrity, and/or perceived increases in understanding about the topics presented in the tutorial. Students provided positive feedback about the tutorials and indicated that they had a better understanding of plagiarism and learned something new. "Jackson (2006) reported increased pre- to post-intervention scores on basic knowledge and skills tests. Overall, the findings from studies examining online tutorials suggest that students can benefit from completing short lessons about plagiarism and academic integrity.

\section{Blended instruction}

Three of the reviewed articles studied the effectiveness of blended approaches to promote academic integrity (Table 3). Bendriss et al. (2015) examined an intervention aimed to enhance students' research skills. In this study, students completed four or eight online information literacy modules that included readings, videos, assignments, and quizzes before attending nine weekly face-to-face sessions with a librarian. The modules and classes addressed a number of issues such as academic integrity, plagiarism, APA documentation style, advanced search techniques, and reference management software. The authors provided evidence of effectiveness in terms of faculty and 


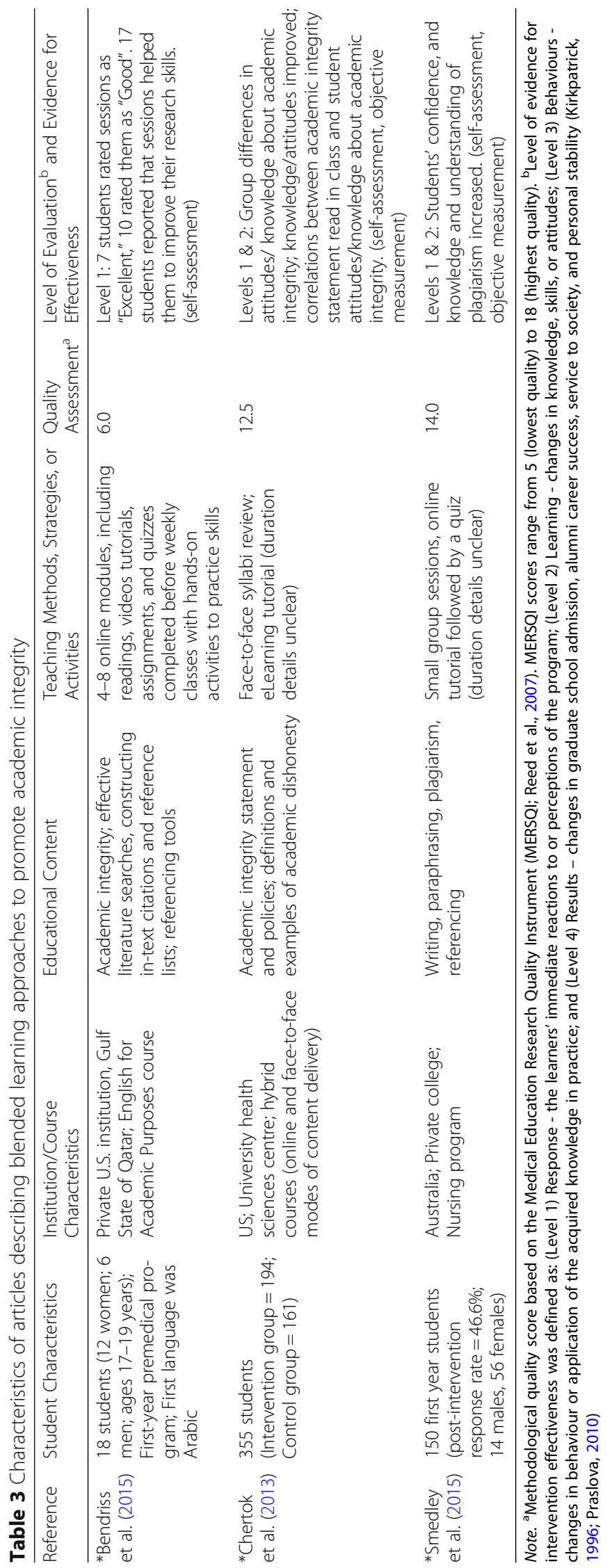


students' satisfaction with the intervention. Using a similar blended approach, "Smedley, Crawford, and Cloete (2015) combined in-class library sessions with hands-on activities to practice paraphrasing and referencing with an online tutorial about understanding plagiarism that ended with an online quiz. Analyses of survey data revealed that students' general knowledge and understanding about plagiarism improved significantly following the intervention.

"Chertok, Barnes, and Gilleland (2013) studied the effectiveness of a simplified (blended) approach to promoting academic integrity. All students participated in a face-to-face session on the first day of a course, which involved a detailed presentation of the syllabus that included the university's academic integrity statement. Students in the intervention group also completed an online tutorial that included definitions and examples of academic dishonesty. Chertok et al. reported significant differences in attitudes and knowledge about academic integrity between control and intervention groups following the tutorial. Changes in attitude and acquired knowledge about academic integrity were also associated with female gender, and hearing the university's academic integrity statement in other classes.

\section{Quality assessment}

Several important study limitations, such as small sample sizes, low response rates, and/ or low statistical power ("Chertok, Barnes, and Gilleland, 2013; "Dee and Jacob, 2012; "Henslee, Goldsmith, Stone, and Krueger, 2015; "Liu, Lo, and Wang, 2013; "Morgan and Hart, 2013; "Smedley, Crawford, and Cloete, 2015), studies of a single institution only ("Chertok, Barnes, and Gilleland, 2013; "Fenster, 2016), and lack of random assignment ("Morgan and Hart, 2013; "Schuetze, 2004) were cited in the reviewed articles. We also noted that the time that participants spent completing homework assignments was not taken into account ("Schuetze, 2004), skills or student outcomes were not measured (e.g., "Elander, Pittam, Lusher, Fox, and Payne, 2010; "Jackson, 2006), or skills may not be generalizable to other settings (e.g., "Chertok, Barnes, and Gilleland, 2013; "Landau, Druen, and Arcuri, 2002). These limitations were reflected in the study quality scores. MERSQI scores across all studies ranged from 7.0 to $16.0(M=11.5, S D=2.7$; see Tables 1, 2 and 3). The mean MERSQI score for studies examining face-to-face instruction for promoting academic integrity was $11.45(S D=2.9$, Range $=7.0-16.0)$. For studies examining e-learning tutorials, the mean MERSQI score was $11.6(S D=2.9$, Range = 9.0-15.0), and for studies examining blended approaches, the mean MERSQI score was 11.3 ( $S D=$ 2.9 , Range $=8.0-13.5$ ). Lower (scores $=5.0-9.3$ ) and moderate (scores $=9.4-13.6)$ quality scores (6 and 10 studies, respectively) were largely due to lower ratings in the study design, sampling, type of data, and outcomes domains. The level of evidence for intervention effectiveness was defined as: Level $1(n=11)$; Level $2(n=11)$; Level $3(n=3)$; and Level 4 $(n=2)$. Of note is that eight studies collected only Level 1 evidence (i.e., self-assessment surveys to collect information about satisfaction, attitudes, perceptions, and opinions) for the effectiveness of the interventions.

\section{Discussion}

The primary goals of the present study were to identify peer-reviewed research that evaluated educational interventions designed to promote academic integrity and to identify the 
demographic or contextual factors contributing to the success of the intervention. The reviewed studies reported that students who attended plagiarism prevention workshops increased their perceived understanding of plagiarism ("Barry, 2006), strengthened their knowledge about plagiarism and paraphrasing skills, and reduced the incidence of overlapping words and word strings in their written work ("Landau, Druen, and Arcuri, 2002). E-learning tutorials were effective in reducing the occurrence of plagiarism ("Belter and Pré, 2009; "Dee and Jacob, 2012), and enhancing knowledge and attitudes regarding academic integrity ("Chertok, Barnes, and Gilleland, 2013) and plagiarism ("Curtis, Gouldthorp, Thomas, O'Brien, and Correia, 2013). Assignments related to the plagiarism theme integrated into the semester long face-to-face research methods courses ("Estow, Lawrence, and Adams, 2011) and online faculty-led discussions were also helpful for increasing the understanding of plagiarism and knowing how to avoid it ("Morgan and Hart, 2013).

Although a variety of teaching methods in various learning environments were implemented in the reviewed studies (with direct instruction being implemented most often), it was difficult to determine whether any one or specific combination of teaching and learning strategies was most effective in promoting academic integrity. This would have been helpful from a practical perspective as many post-secondary instructors find it challenging to create/select meaningful learning activities that stress the importance of acting with integrity and are aligned with specific learning objectives, are pedagogically sound, and are transferable and lasting. Many would agree, however, that the components of effective teaching (regardless of discipline or topic area) are multi-faceted, and include careful lesson planning; clear communication of goals, objectives, and expectations for assessment and success; and feedback (Ambrose, Bridges, Dipietro, Lovett, and Norman, 2010; Hattie, 2009). Only one of the studies reviewed compared the effectiveness of two or more conditions within the intervention to promote academic integrity, and reported that providing students with task-specific feedback was most beneficial (i.e., "Landau, Druen, and Arcuri, 2002). Research also shows that problem-based learning (requiring the solving of open-ended problems in collaboration with others) and other student-centred pedagogies are more effective than traditional lecturing in helping students construct knowledge (see Hmelo-Silver, 2004), and develop their critical thinking skills and self-confidence (e.g., Tiwari, Lai, So, and Yuen, 2006). Again, only one reviewed study (i.e., "Trautner and Borland, 2013) examined the impact of what may be considered a student-centred approach (case-study/discussion/problem-solving) to academic integrity learning, however, comparisons to another strategy were not made.

Regardless of the specific strategies or activities implemented, there is research evidence demonstrating that positive classroom climate and instructor enthusiasm can dramatically increase student engagement and intrinsic motivation, positively influence learning outcomes (Ambrose et al., 2010; Hattie, 2009), and reduce cheating behaviour (Orosz, Tóth-Király, Bothe, Kusztor, Kovács, and Jánvári, 2015). The reviewed studies did not report the effect of instructor characteristics on the effectiveness of the educational interventions for promoting academic integrity and preventing academic misconduct, and it would be interesting and informative to examine this further.

The success or failure of a given educational intervention may also depend, in part, on the broader cultural and institutional context in which it is set. Contextual factors play key roles in determining norms regarding academic integrity and misconduct (e.g., Chen and Macfarlane, 2016), the importance in addressing academic integrity issues 
and the need for the promotion of values associated with them, and the perceived necessity to implement educational interventions and evaluate their effectiveness. Although some of the reviewed articles did describe a few characteristics of the educational settings in which the interventions were set, these factors were not examined formally. The majority of the studies reviewed were conducted in the United States, followed by Australia and United Kingdom; researchers in these countries have largely led the way in academic integrity research, suggesting that integrity issues are a priority in these regions. However, researchers in other countries are beginning to follow suit (see Bretag, 2016). Of relevance to us, our search did not identify any Canadian studies, suggesting that studies evaluating educational interventions for the promotion of academic integrity in Canadian classrooms and campuses are not being conducted. If this is the case, researchers have an opportunity to implement and evaluate the effectiveness of educational interventions designed to promote academic integrity in the Canadian context, as the academic culture in Canada may be quite different from that observed and described in other countries.

Student characteristics likely influence the effectiveness of an intervention designed to teach students about academic integrity and academic misconduct. Interestingly, only two of the reviewed studies explored the influence of participant age or education level on the intervention effectiveness, with the youngest students (those $<24$ years of age) showing the biggest improvements in understanding plagiarism ("Smedley, Crawford, and Cloete, 2015), but year in college was not a significant factor for intervention success ("Dee and Jacob, 2012). Younger students may be more tolerant of cheating overall (Nonis and Swift, 2001), but may also be receptive to specific teaching about academic integrity early in their postsecondary studies. Gains in understanding academic integrity may not be as great for older students or graduate students following an educational intervention because they may already understand the issues of academic integrity, believe that cheating is immoral or unethical, and/or be highly motivated to learn thereby engaging in fewer acts of academic misconduct (Sheard, Markham, and Dick, 2003).

Another important factor that may influence the effectiveness of educational interventions designed to promote academic integrity is gender. Four of the reviewed studies included participant gender as a variable in the analyses. Two studies did not find evidence of gender differences in intervention effectiveness ("Dee and Jacob, 2012; "Fenster, 2016), whereas two reported that women (but not men) had more appropriate attitudes towards and higher levels of knowledge about academic integrity following the interventions ("Chertok, Barnes, and Gilleland, 2013; "Smedley, Crawford, and Cloete, 2015). It is unclear from the reviewed studies why gender differences in the effectiveness of the interventions were observed; however, it is possible that such differences are associated with gender differences in the cheating behaviours. Research shows that men engage in more dishonest academic behaviour than do women (Davis et al., 2012; Nonis and Swift, 2001; Whitley, Nelson, and Jones, 1999), and are more tolerant of workplace cheating (Nonis and Swift, 2001). In a large-scale study of more than 6000 high school and post-secondary students, Davis et al. reported significantly lower cheating rates for women than men. Although women reported that they cheat significantly less often than do men, they may plagiarize significantly more (Hensley, Kirkpatrick, and Burgoon, 2013; Patrzek et al., 2015; Martin, Rao, and Sloan, 2009). 
Gender differences in intervention effectiveness may also be related to gender differences for reasons for committing academic misconduct in the first place. For example, gender differences have been found for time management issues, such as procrastination (Patrzek et al., 2015). There is also evidence to suggest that students with lower grades engage in more acts of academic dishonesty than those with higher grades because they are compensating for their lack of ability or are not making the effort in their schoolwork required to achieve their desired results (Hensley et al., 2013). Moreover, students who cheat also report the use of self-handicapping strategies such as procrastination, blaming others, or making excuses to justify their personal failure (Anderman, Griesinger, and Westerfield, 1998). Further research in needed to shed light on gender differences in academic dishonesty and effectiveness of interventions designed to promote academic integrity.

Overall quality of many of the studies reviewed was relatively low to moderate, somewhat limiting the generalizability of the findings from those particular studies. Lower overall quality scores largely stemmed from lower ratings in the study design, sampling, type of data, and outcomes domains. For example, many of the reviewed studies obtained Level 1 evidence for intervention effectiveness (Kirkpatrick, 1996), and lacked measurement of higher level student outcomes. Satisfaction and attitudes may be one source of data to collect when determining whether an intervention should be developed further or implemented on a larger scale because it may serve as a proxy for probable uptake, but it may not be a reasonable measure of whether an educational intervention "works." The collection of data regarding learners' reactions to or perceptions of a program is quite easy and therefore common, but is typically weakly associated with learning (i.e., gains in knowledge and skills; transfer of knowledge and skills to other settings; quickly retrieving knowledge and skills from memory; Brown, Roediger, and McDaniel, 2014) or longer-term outcomes (see Praslova, 2010; Schilling and Applegate, 2012 for reviews). Thus, future work may involve the use a longitudinal, mix-methods approaches and collect data regarding demographic and contextual factors, emotional influences, motivational factors, and various long-term outcomes across multiple time-points in large and diverse samples to understand the effectiveness of interventions. Longer term outcomes, such as graduate school admission, alumni career success, service to society, and personal stability (e.g., making well-thought-out life decisions and being consistently honest in various circumstances) should be considered when determining the level of effectiveness of educational intervention designed to promote academic integrity.

\section{Limitations of present review and future research}

Although we took great care to follow standard procedures for searching and selecting peer-reviewed research articles, we recognize several limitations of this review. Our search consisted of an electronic database search and we did not conduct hand searches of relevant journals or cited reference searches; thus, the studies we found were limited to those that were identifiable by our selected keywords. The strength of keyword searches is that it is a quick, high precision way of finding some articles but it can also be problematic because of its low average sensitivity (e.g., Linder, Kamath, Pratt, Saraykar, and Volk, 2015). Including additional keywords, adjusting the use of the 
logical operators, and using other search strategies may have allowed us to cast a broader net to locate more articles relevant to the aims of this review. Our intent, however, was not to locate articles that dealt with the prevention of other integrity issues present in academia, such as research integrity and scientific misconduct. While a related and important topic (see Fanelli, 2009 and Stroebe, Postmes, and Spears, 2012 for reviews on scientific fraud), identification of these articles may have resulted in more articles to screen, but would not guarantee the exclusion of an even larger number of articles that did not meet the criteria for the present review.

Another avenue we could have taken to broaden our search was to capture the research literature on academic integrity interventions used in K-12 education. During our screening and review process, we did not find any studies (or reviews) investigating the effectiveness of academic integrity interventions implemented at the K-12 levels. At the high school level, the strategies that educators use to promote of academic integrity may differ from those implemented in higher education (e.g., they may be more or less targeted to the development of specific skills or the terminology used to describe academic integrity issues may be different). Some authors contend that high school educators may not realize the seriousness of the problem in their schools (Evans and Craig, 1990), or may feel ill-equipped to deal with academic integrity issues - an assertion that requires investigation. Future studies could examine the strategies used by high school educators to help students understand the importance of acting with integrity in their schoolwork, and to determine their impact on student behaviours in the classroom and long-term outcomes.

Our review was also limited to studies that evaluated relatively brief ("one-off") educational interventions. Publication bias may also have limited our ability to evaluate and describe educational interventions for promoting academic integrity that were not successful in improving students' attitudes and perceptions, knowledge and skills, and student outcomes. Future research could expand/revise the inclusion/exclusion criteria to allow for the retrieval and review of studies in both peer-reviewed and grey literature that have examined the effectiveness of more comprehensive interventions to promote academic integrity.

To our knowledge, we are the first to assess the quality of the studies examining educational interventions for academic integrity using the MERSQI (Cook and Reed, 2015), a tool that was developed and has been used to appraise medical education research. This may be seen as a limitation, as some may argue that implementing a tool developed to evaluate education research in one discipline may not provide a useful framework when applied to another context. The investigation of the generalizability of research evaluation tools is an important avenue for future research; a study comparing ratings obtained using the MERSQI to ratings obtained using other research evaluation tools would provide evidence for the validity of MERSQI scores. Another challenge in using the MERSQI was the low interrater reliability for some subscales, suggesting that more detailed information be provided with the instrument and that raters acquire additional training and practice, and research experience prior to its use. Despite these limitations, we found that a slight modification to the MERSQI allowed us to extract important information about the methodological quality of the reviewed studies and calculate a quantitative value for comparison purposes. 


\section{Conclusions}

There are several advantages to using a preventative approach to academic misconduct. The explicit teaching of expectations around academic integrity and academic dishonesty, and a focus on proper citing and paraphrasing, and avoidance of plagiarism has the potential to reduce unintentional academic misconduct cases, in which there was a misunderstanding about policies or rules of citation. Fewer suspected cases of academic dishonesty means reduced administrative burden and emotional distress for all parties involved ("Belter and Pré, 2009). As the present review has shown, the promotion of academic integrity can be done in online formats or in short face-to-face sessions. An advantage of adding an online tutorial to a face-to-face course is that it can allow instructors to devote more in-class time to course content ("Belter and Pré, 2009). Although short workshops and tutorials can result in behaviour change, efforts to increase students' knowledge and skills as they relate to academic integrity are likely to result in greater success for students over the long term if practice or hands-on experiences are included in the teaching approach. Face-to-face lectures and e-learning tutorials can be similarly effective when the teaching strategies implemented are suitable to deliver the content (Clark, 1994) and encourage deep understanding (Löfström, 2016). Thus, the effectiveness of an educational intervention to promote academic integrity depends on the instructional methods utilized, and environmental and individual factors on students' perceptions, learning outcomes, and behaviors.

Although there is debate about whether the prevalence of academic dishonesty is increasing (see Culwin, 2006; Curtis and Vardanega, 2016), current rates may be related to the increasing availability of internet sources (see Duggan, 2006), an underestimation of the extent of the problem, or an unwillingness to engage in formal procedures for dealing with misconduct (Brimble and Stevenson-clarke, 2006). As we have found in the current review, even simple education interventions have the potential to create changes in attitudes, knowledge, and skills related to academic integrity ("Chertok et al., 2013). Thus, continued efforts by educational institutions must be made to change the academic culture from one where cheating is the norm to one where integrity is expected.

Abbreviation

MERSQI: Medical Education Research Study Quality Instrument

\section{Acknowledgements}

The authors would like to thank Christy Miyanishi for her assistance in the article search, retrieval, and selection, and Dr. Ryan Los for his careful review of the manuscript.

Funding

This research and publication was supported by The Centre for the Advancement of Teaching and Learning, University of Manitoba. No external funding was received.

Availability of data and materials

The data will be shared upon request.

Authors' contributions

BMS and AY were involved in all aspects of this review from article searching, screening, and selection, data extraction, analysis, to writing of the manuscript. Both authors read and approved the final manuscript.

Competing interests

The authors declare that they have no competing interests. 


\section{Author details}

${ }^{1}$ Centre for the Advancement of Teaching and Learning, University of Manitoba, 65 Dafoe Road, Winnipeg, MB R3T 2N2, Canada. ${ }^{2}$ Present Address: Paul R. MacPherson Institute for Leadership, Innovation and Excellence in Teaching, Mills Library L504, McMaster University, 1280 Main Street West, Ontario, Hamilton L8S 4K1, Canada.

Received: 30 May 2018 Accepted: 21 August 2018

Published online: 12 September 2018

\section{References}

\section{*Studies reviewed}

*Barry ES (2006) Can paraphrasing practice help students define plagiarism? Coll Stud J 40(2):377-384 Retrieved from https:// eric.ed.gov/?id=EJ765334

* Belter R, Pré AD (2009) A strategy to reduce plagiarism in an undergraduate course. Teach Psychol 36(4):257-261 https://doi. org/10.1080/00986280903173165

*Bendriss R, Saliba R, Birch S (2015) Faculty and librarians' partnership: designing a new framework to develop information fluent future doctors. J Acad Librarianship 41(6):821-838 https://doi.org/10.1016/j.acalib.2015.09.003

*Chertok IRA, Barnes ER, Gilleland D (2013) Academic integrity in the online learning environment for health sciences students. Nurse Educ Today 34(10):1324-1329 https://doi.org/10.1016/..nedt.2013.06.002

*Curtis GJ, Gouldthorp B, Thomas EF, O'Brien GM, Correia HM (2013) Online academic-integrity mastery training may improve students ' awareness of, and attitudes toward, plagiarism. Psychol Learn Teach 12(3):282-289

*Dee TS, Jacob BA (2012) Rational ignorance in education: a field experiment in student plagiarism. J Hum Resour 47(2):397-434 https://doi.org/10.1353/jhr.2012.0012

*Elander J, Pittam G, Lusher J, Fox P, Payne N (2010) Evaluation of an intervention to help students avoid unintentional plagiarism by improving their authorial identity. Assess Eval Higher Educ 35(2):157-171 https://doi.org/10.1080/ 02602930802687745

*Estow S, Lawrence EK, Adams KA (2011) Practice makes perfect: improving students' skills in understanding and avoiding plagiarism with a themed methods course. Teach Psychol 38:255-258 https://doi.org/10.1177/0098628311421323

*Fenster J (2016) Teaching note - evaluation of an avoiding plagiarism workshop for social work students. J Soc Work Educ 7797:242-248 https://doi.org/10.1080/10437797.2016.1151278

*Ford PJ, Hughes C (2012) Academic integrity and plagiarism: perceptions and experience of staff and students in a school of dentistry: a situational analysis of staff and student perspectives. Eur J Dent Educ 16(1):180-186 https://doi.org/10.1111/j. 1600-0579.2011.00695.x

*Froese AD, Boswell KL, Garcia ED, Koehn L, Nelson JM (1995) Citing secondary sources: can we correct what students do not know? Teach Psychol 22(4):235-238

*Gunnarsson J, Kulesza WJ, Pettersson A (2014) Teaching international students how to avoid plagiarism: librarians and faculty in collaboration. J Acad Librarianship 40(3-4):413-417 https://doi.org/10.1016/j.acalib.2014.04.006

*Henslee AM, Goldsmith J, Stone NJ, Krueger M (2015) An online tutorial vs. pre-recorded lecture for reducing incidents of plagiarism. AM J Eng Educ (AJEE) 6(1):27-32

*Jackson PA (2006) Plagiarism instruction online: assessing undergraduate students' ability to avoid plagiarism. College Research Libraries 67:418-428. https://doi.org/10.5860/crl.67.5.418

*Kirsch BA, Bradley L (2012) Distance education and plagiarism prevention at the University of South Carolina Upstate. J Library Inform Serv Dis Learn 6(2):79-99. https://doi.org/10.1080/1533290X.2012.693903

*Landau JD, Druen PB, Arcuri JA (2002) Methods for helping students avoid plagiarism. Teach Psychol 29(2):112-115

*Liu G-Z, Lo H-Y, Wang H-C (2013) Design and usability testing of a learning and plagiarism avoidance tutorial system for paraphrasing and citing in English: a case study. Computers and Education 69 https://doi.org/10.1016/j. compedu.2013.06.011

*Morgan, L., \& Hart, L. (2013). Promoting academic integrity in RN-BSN program. Nurs Educ Perspect, 34(4), 240-243. Retrieved from file:///users/anderann/Downloads/report-promoting-academic-integrity.pdf

*Schuetze P (2004) Evaluation of a brief homework assignment designed to reduce citation problems. Teach Psychol 31(4):257-259

*Smedley A, Crawford T, Cloete L (2015) An intervention aimed at reducing plagiarism in undergraduate nursing students. Nurse Educ Pract 15(3):168-173 https://doi.org/10.1016/..nepr.2014.12.003str

*Trautner MN, Borland E (2013) Using the sociological imagination to teach about academic integrity. Teach Sociol 41(4):377-388 https://doi.org/10.1177/0092055X13490750

Ambrose SA, Bridges MW, Dipietro M, Lovett MC, Norman MK (2010) How learning works: 7 research-based principles for smart teaching. John Wiley \& Sons, San Francisco, CA

Anderman EM, Griesinger T, Westerfield G (1998) Motivation and cheating during early adolescence. J Educ Psychol 90(1):84-93

Andersson S, Larsson AL, \& Lofkvist J (2008). Refero: An antiplagiarism tutorial. Retrieved from http://refero.Inu.se/english/

Bailey PA (2001) Academic misconduct: responses from deans and nurse educators. J Nurs Educ 40(3):124-131 https://doi. org/10.3928/0148-4834-20010301-07

Barnhardt B, Ginns P (2016) Psychological teaching-learning contracts: academic integrity and moral psychology. Ethics \& Behavior 8422:10508422.2016.1167604 https://doi.org/10.1080/10508422.2016.1167604

Bertram Gallant T (2008) Moral panic: the contemporary context of academic integrity. ASHE High Educ Rep 33:1-12 https:// doi.org/10.1002/aehe.3305

Bretag T (ed) (2016) Handbook of academic integrity. SpringerNature, Singapore

Brimble M, Stevenson-Clarke P (2006) Managing academic dishonesty in Australian universities: Implications for teaching, learning and scholarship. Accounting, Accountability and Performance 12(1):32-63. Retrieved from https://ssrn.com/ abstract=1884052

Brown PC, Roediger HL, McDaniel MA (2014) Make it stick: the science of successful learning. Harvard University, Cambridge

Chen, S., \& Macfarlane, B. (2016). Academic integrity in China. In T. Bretag (E.d), Handbook of academic integrity (pp. 99-105). Singapore: Springer Nature 
Clark R (1994) Media will never influence learning. Educ Technol Res Dev 42(1):21-29 https://doi.org/10.1007/BF02299088 Cook DA, Reed DA (2015) Appraising the quality of medical education research methods: the medical education research study quality instrument and the Newcastle-Ottawa scale-education. Acad Med 90(8):1067-1076 https://doi.org/10.1097/ ACM. 0000000000000786

Cook DA, West CP (2012) Conducting systematic reviews in medical education: a stepwise approach. Med Educ 46(10):943-952. https:/doi.org/10.1111/j.1365-2923.2012.04328.x

Curtis GJ, Vardanega L (2016) Is plagiarism changing over time? A 10-year time-lag study with three points of measurement. Higher Educ Res Dev 35(6):1167-1179 https://doi.org/10.1080/07294360.2016.1161602

Davis SF, Grover CA, Becker AH, McGregor LN (2012) Academic dishonesty: prevalence, determinants, techniques, and punishments. Teach Psychol 19(1):16-21

Driscoll M (2002) Blended learning: Let's get beyond the hype. e-Learning 3(3):54

Duggan F (2006) Plagiarism: Prevention, practice and policy. Assessment \& Evaluation in Higher Education 31(2):151-154 http://doi.org/10.1080/02602930500262452

Earle J, Maynard R (2013). Common guidelines for education Research and Development. National Science Foundation

Evans ED, Craig D (1990) Teacher and student perceptions of academic cheating in middle and senior high schools. J Educ Res 84(1):44-53. Retrieved from http://www.jstor.org/stable/40539681

Fanelli D (2009) How many scientists fabricate and falsify research? A systematic review and meta-analysis of survey data. PLoS One 4(5):e5738

Galloway MK, Conner J (2015) Perpetuating privilege: students' perspectives on the culture of a high-performing and highpressure high school. Educ Forum 79(2):99-115 https://doi.org/10.1080/00131725.2014.1002592

Greenberger S, Holbeck R, Steele J, Dyer T (2016) Plagiarism due to misunderstanding: online instructor perceptions. J Scholarsh Teach Learn 16(6):72 https://doi.org/10.14434/josotl.v16i6.20062

Hattie J (2009) Visible learning: A synthesis of over 800 meta-analyses relating to achievement. Oxon: Routledge, Abingdon https://doi.org/10.4324/9780203887332

Hensley LC, Kirkpatrick KM, Burgoon JM (2013) Relation of gender, course enrollment, and grades to distinct forms of academic dishonesty. Teach High Educ 18(8):895-907 https://doi.org/10.1080/13562517.2013.827641

Hmelo-Silver, C. E. (2004). Problem-based learning: what and how do students learn? Educ Psychol Rev, 16(3), 235-266. doi: 1040-726X/04/0900-0235/0.

Jackson PA (n.d.) Plagiarism: the crime of intellectual kidnapping. San Jose: San Jose State University. Retrieved from https:/ library.sdsu.edu/guides/tutorial.php?id=28

Kirkpatrick, D. (1996). Great ideas revisited. Training \& Development. https://eric.ed.gov/?id=EJ515660

Krueger $L$ (2014) Academic dishonesty among nursing students. J Nurs Educ 53(2):77-87 https://doi.org/10.3928/0148483420140122-06

Linder SK, Kamath GR, Pratt GF, Saraykar SS, Volk RJ (2015) Citation searches are more sensitive than keyword searches to identify studies using specific measurement instruments. J Clin Epidemiol 68(4):412-417 https://doi.org/10.1016/j.jclinepi. 2014.10.008

Löfström E (2016) Role-playing institutional academic integrity policy-making: using researched perspectives to develop pedagogy. Int J Educ Integr 12(5):1-14 https://doi.org/10.1007/s40979-016-0011-0

Lucas G, Friedrich J (2005) Individual differences in workplace deviance and integrity as predictors of academic dishonesty. Ethics and Behavior 15(1):15-35 https://doi.org/10.1207/x15327019eb1501_2

Martin DE, Rao A, Sloan LR (2009) Plagiarism, integrity, and workplace deviance: a criterion study. Ethics \& Behavior 19(1):36-50 https://doi.org/10.1080/10508420802623666

Maxwell A, Curtis GJ, Vardanega L (2006) Plagiarism among local and Asian students in Australia. Guidance \& Counselling 21(4):210-215

Miriam-Webster. n.d.. Workshop [Def. 3]. Retrieved May 22, 2017, from https:/www.merriam-webster.com/dictionary/workshop

Moher D, Liberati A, Tetzlaff J, Altman DG (2009) Preferred reporting items for systematic reviews and meta-analyses: the PRISMA statement. Phys Ther 89(9):873-880 https://doi.org/10.1136/bmj.b2535

Nonis S, Swift CO (2001) An examination of the relationship between academic dishonesty and workplace dishonesty: a multicampus investigation. J Educ Bus 77(2):69-77 https://doi.org/10.1080/08832320109599052

Oran NT, Can HO, Senol S, Hadimli AP (2015) Academic dishonesty among health science school students. Nurs Ethics:1-3 https://doi.org/10.1177/0969733015583929

Orosz G, Tóth-Király I, B the B, Kusztor A, Kovács ZU, Jánvári M (2015) Teacher enthusiasm: a potential cure of academic cheating. Front Psychol 6:1-12. https://doi.org/10.3389/fpsyg.2015.00318

Patrzek J, Sattler S, van Veen F, Grunschel C, Fries S (2015) Investigating the effect of academic procrastination on the frequency and variety of academic misconduct: a panel study. Stud High Educ 40(6):1014-1029. https://doi.org/10.1080/ 03075079.2013.854765

Praslova L (2010) Adaptation of Kirkpatrick's four level model of training criteria to assessment of learning outcomes and program evaluation in higher education. Educ Assess Eval Account 22(3):215-225 https://doi.org/10.1007/s1 1092-010-9098-7

Reed DA, Cook DA, Beckman TJ, Levine RB, Kern DE, Wright SM (2007) Association between funding of published medical education research. JAMA 298(9):1002-1009 https://doi.org/10.1001/jama.298.9.1002

Roig M (1999) When college students' attempts at paraphrasing become instances of potential plagiarism. Psychol Rep 84(3): 973-982 https://doi.org/10.2466/pr0.1999.84.3.973

Schilling K, Applegate R (2012) Best methods for evaluating educational impact: a comparison of the efficacy of commonly used measures of library instruction. J Med Library Assoc 100(4):258-269. https://doi.org/10.3163/1536-5050.100.4.007

Shamseer L, Moher D, Clarke M, Ghersi D, Liberati A, Petticrew M, PRISMA-P Group (2015) Preferred reporting items for systematic review and meta-analysis protocols (PRISMA-P) 2015: elaboration and explanation. BMJ (Clinical Research Ed) 349(3)::97647 https://doi.org/10.1136/bmj.g7647

Sheard J, Markham S, Dick M (2003) Investigating differences in cheating Behaviours of IT undergraduate and graduate students: the maturity and motivation factors. Higher Educ Res Dev 4360:91-108 https://doi.org/10.1080/0729436032000056526

Standards for Reporting on Humanities-Oriented Research in AERA Publications: American Educational Research Association. (2009). Educational Researcher, 38(6), 481-486. https://doi.org/10.3102/0013189X09341833 
Stroebe W, Postmes T, Spears R (2012) Scientific misconduct and the myth of self-correction in science. Perspect Psychol Sci 7(6):670-688 https://doi.org/10.1177/1745691612460687

Tiwari A, Lai P, So M, Yuen K (2006) A comparison of the effects of problem-based learning and lecturing on the development of students' critical thinking. Med Educ 40(6):547-554. https://doi.org/10.1111/j.1365-2929.2006.02481.x

Web Finance. n.d.. Tutorial [Def 1.]. Retrieved May 22, 2016, from http://www.businessdictionary.com/definition/tutorial.html Whitley BE, Nelson AB, Jones CJ (1999) Gender differences in cheating attitudes and classroom cheating behavior: a metaanalysis. Sex Roles 41(9-10):657-677 https://doi.org/10.1023/A:1018863909149

Wideman M (2011) Caring or collusion? Academic dishonesty in a school of nursing. Can J Higher Educ Revue Canadienne 41(2):28-43

Ready to submit your research? Choose BMC and benefit from:

- fast, convenient online submission

- thorough peer review by experienced researchers in your field

- rapid publication on acceptance

- support for research data, including large and complex data types

- gold Open Access which fosters wider collaboration and increased citations

- maximum visibility for your research: over $100 \mathrm{M}$ website views per year

At $\mathrm{BMC}$, research is always in progress.

Learn more biomedcentral.com/submission 